


\begin{tabular}{llll}
\hline \multirow{2}{*}{$\begin{array}{l}\text { Ivana V. Yang } \\
\text { University of Colorado }\end{array}$} & $\begin{array}{l}\text { University of Colorado } \\
\text { Denver, Aurora, CO, USA }\end{array}$ & $\begin{array}{l}\text { Denver, 12700 East 19th } \\
\text { ivana.yang@ucdenver.edu } \\
\end{array}$ \\
& $\begin{array}{l}\text { Avenue, 8611, Aurora, CO } \\
80045, \text { USA }\end{array}$
\end{tabular}

\section{Epigenetics and prenatal influences on asthma and allergic airways disease}

\section{Educational aims}

- Describe how genetic studies have explained a small portion of asthma heritability

- Discuss how epigenetic marks are influenced by the environment and are important in T-cell lineage differentiation

- Describe animal studies of the role of DNA methylation in the development of allergic airway disease

- Summarise human studies on the role of DNA methylation in asthma and allergy

\section{Introduction}

Asthma is a complex, heritable disease that has been increasing in prevalence, incidence and severity [1], although recent evidence suggests that the prevalence of asthma and allergies may have come to a plateau in developed countries [2]. Several separate lines of evidence support a role for epigenetics in asthma. First, asthma, like epigenetic mechanisms, is heritable. While asthma is a strongly familial condition (36-79\% heritability) with a non-Mendelian pattern of inheritance and polymorphisms in more than 100 genes [3-6], these associations have infrequently been replicated and genetics has explained only a small portion of the aetiology of this disease [4]. Second, asthma, like epigenetic mechanisms, shows a parentof-origin transmission of inheritance with an affected mother significantly more likely to transmit the disease than an affected father [7]. These parent-of-origin effects may result from immune interactions between the fetus and the mother [8]. Alternatively, the maternal effect may be the result of epigenetically regulated genomic imprinting [9]. Several known genes show parent-of-origin effects on allergic disease; these genes include the Fc\&RI- $\beta$ locus [10], and the Spink5 gene [11]. Third, asthma, like epigenetic mechanisms $[12,13]$, is affected by in utero exposures
Statement of Interest None declared.

This article has been modified from an ERS School Course held in Barcelona, Spain, in 2013. The original slides and material can be found at www. ers-education.org

\section{(c) (i) () ERS 2014}

HERMES syllabus link: modules A.1, B. 6 
$[14,15]$. Prenatal exposure to maternal and grand-maternal cigarette smoke [16-18] and traffic-related air pollution [19, 20] are among in utero exposures that contribute to the development of this disease. By contrast, higher maternal fruit and vegetable intake and oily fish consumption during gestation have been associated with a lower risk of asthma [21]. Fourth, asthma, like epigenetics, is influenced by the general environment [22]. Environmental factors are known to play important roles in the pathogenesis of asthma, both in terms of main effects and those exerted indirectly through complex interactions with gene variants [23]. The dramatic increase in the prevalence, incidence and severity of asthma over the past 20 years provides strong evidence that exposures, including diet, play an important role in the development of this disease; these changes have occurred too rapidly to be accounted for by changes in primary DNA sequence alone. While allergens are classically associated with asthma [24], many other exposures, including smoking behaviour $[23,25]$, are associated with the development and progression of this disease, and several of these agents have been shown to alter epigenetic marks. Finally, asthma is an immune-mediated disease characterised mainly by skewing toward a T-helper cell (Th) 2 phenotype although other T-cell subtypes may be involved [26]. Epigenetic mechanisms regulate expression of transcription factors that are involved in T-cell differentiation (Th1, Th2, and regulatory T-cells (Tregs) [27-34].

\section{The role of the environment and in utero exposures in modulating the epigenome}

Unlike an individual's genetic make-up, epigenetic marks can be influenced much more easily by exposures, diet and ageing. Randy Jirtle's seminal experiments in mice showed that maternal diet supplemented with methyl donors (folic acid, vitamin B12, choline and betaine) shifts coat colour distribution of progeny towards the brown pseudoagouti phenotype and that this shift in coat colour resulted from an increase in DNA methylation in a transposon adjacent to the agouti gene $[12,13]$. These studies also revealed that mice with yellow coat colour are obese and develop cancer, suggesting for the first time that changes in DNA methylation caused by diet in utero may be linked to disease development. Other studies have shown that pesticides and fungicides can alter the methylome resulting in changes in male fertility [35], and that ageing is also associated with changes in DNA methylation and gene expression $[36,37]$. The concepts associated with environmental epigenetics were reviewed recently [38].

More recent evidence suggests that environmental exposures relevant to the development of asthma, such as air pollution and cigarette smoke, also affect the epigenome. Decreased DNA methylation in peripheral blood (as measured by LINE-1 repeats) was found to be associated with exposure to particulate matter with an aerodynamic diameter $<2.5 \mu \mathrm{m}\left(\mathrm{PM}_{2.5}\right)$ amongst 718 elderly individuals in the Boston area [39] and although this correlated with time-dependent variables such as day of the week and season, there was no association with air pollutionrelated health effects. Another study demonstrated that hypomethylation of the iNOS (Nos2) promoter in buccal cells was associated with exhaled nitric oxide (NO) levels and PM2.5 exposure among 940 participants in the Children's Health Study [40]. Several epidemiological studies have examined the relationship between exposure to cigarette smoke and epigenetic marks. Among 384 children, a global reduction in DNA methylation, as measured by the extent of methylation of Alu repeats and differential methylation of 8 specific CpC motifs, was found to be associated with in utero smoke exposure [41]. 15 specific genomic loci were significantly associated with current smoking, two with cumulative smoke exposure and three with time since quitting cigarettes in 1085 individuals enrolled in the International COPD Genetics Network and validated in the Boston Early-Onset COPD study $(n=369)$ [42].

In addition to influencing epigenetic marks as a result of direct exposure, in utero exposure to components of air pollution or cigarette smoke results in changes in global and site-specific DNA methylation. Maternal exposure to benzo(a)pyrene, a representative airborne polycyclic aromatic hydrocarbon, was associated with hypermethylation of interferon (IFN) $-\gamma$ in cord blood DNA from 53 participants in the Columbia Center for 
Children's Environmental Health cohort [43]. In another study, global hypomethylation has been associated with maternal smoking and cotinine levels in the umbilical cord blood from 30 newborns [44]. In a birth cohort of 90 women, born 1959-1963 in New York City, prenatal tobacco exposure, measured at the time of pregnancy and not retrospectively reported, was associated with a decrease in Sat2 methylation, but not LINE-1 or Alu methylation [45]. Examination of two differentially methylated regions (DMRs) regulating two imprinted loci ( $\mathrm{H}_{19}$ and $\left.\lg f_{2}\right)$ in infants born to 418 pregnant women demonstrated that infants born to smokers had higher methylation at the $\lg f 2$ DMR than those born to never-smokers or those who quit during pregnancy (no differences were seen in the H19 DMR) [46]. Similarly, DNA methylation in $A x l$, a receptor tyrosine kinase relevant in cancer and immune function, was $2.3 \%$ higher in the peripheral blood of children exposed to maternal smoking in utero [47].

\section{Epigenetic marks and the immune system}

A substantial body of evidence suggests that epigenetic mechanisms affect the expression of cytokines and binding of transcription factors that control the lineage of Th1, Th2, and Treg cells. In the context of Th1/Th2 differentiation, the most extensively studied are the Th1 cytokine IFN- $\gamma$ and the Th2 cytokines interleukin (IL)-4 and IL-13. It has been shown that de novo DNA methyltransferase DNMT3A methylates CPG-53 in the Ifng promoter [27] and cord blood $\mathrm{CD}_{4}^{+}$cells enhance the development of Thr (but not Th2) lineage through progressive demethylation of the Ifng promoter [28]. Methylation of the Ifng promoter was reduced in $\mathrm{CD}^{+}$cells from atopic children in the age range in which hyperproduction of IFN- $\gamma$ occurs, suggesting that DNA methylation at this locus may be a contributing factor in the development of atopy in children. Differentiation of human $\mathrm{CD}_{4}^{+}$cells into the Th2 subtype is accompanied by the appearance of DNase I hypersensitive sites and $\mathrm{CpG}$ demethylation around these DNase I hypersensitive sites within the IL-4 and IL-13 promoters [29-31]. Extensive studies of the Th2 cytokine locus control region (LCR) [32] have shown that rad50 hypersensitive site 7 (RHS7) within the Th2 cytokine LCR undergoes rapid demethylation during Th2 differentiation [33].

In addition to DNA methylation, histone modifications are also important in guiding T-cell differentiation. T-bet and GATA-3 transcription factors control lineage-specific histone acetylation of Ifng and $/ / 4$ loci during Th1/Th2 differentiation [34]. Rapid methylation of $\mathrm{H}_{3} \mathrm{~K}_{9}$ and $\mathrm{H}_{3} \mathrm{~K}_{2} 7$ residues (repressive marks) at the Ifng locus was associated with differentiating Thr cells, while demethylation of $\mathrm{H}_{3} \mathrm{~K} 9$ and methylation of $\mathrm{H}_{3} \mathrm{~K}_{2} 7$ was associated with Th2 differentiation. In a study of human cord blood $\mathrm{CD}_{4}{ }^{+}$cells, histone acetylation marks at the proximal $/ 1 / 3$ promoter were selectively observed in Th2 cells [31], suggesting that permissive histone marks together with DNA demethylation lead to expression of IL-13 in Th2 cells. In aggregate, these studies suggest that DNA methylation and histone modifications are highly dynamic and represent important determinants of Thr and Th2 cell lineages.

Epigenetic mechanisms controlling development of Tregs are also beginning to be explored. Tregs are a unique T-cell lineage with an important role in immunological tolerance whose development is primarily regulated by the transcription factor $\mathrm{FOXP}_{3}$. Evidence for the role of DNA methylation [48] and histone modifications [49] in regulation of $\mathrm{FOXP}_{3}$ expression are summarised in two reviews $[50,51]$.

\section{DNA methylation and asthma: animal studies}

Given the evidence for the strong influence of environmental exposures on epigenetic marks and the role of epigenetic regulation in T-cell differentiation, it is becoming clear that epigenetic changes may be one of the factors to explain the increasing prevalence of asthma. Our group hypothesised that these dietary influences are, at least in part, mediated by the epigenome. To test this hypothesis, we conducted a study in which pregnant female mice were fed either a low or high methylation diet and progeny were sensitised and challenged with ovalbumin [15]. We observed an increase in airway inflammation, serum IgE and airway hyperresponsiveness (AHR) in pups of mothers who were fed the high methylation diet compared 
with those of mothers on the low methylation diet. Furthermore, we demonstrated hypermethylation of 82 gene-associated $\mathrm{CpC}$ islands throughout the genome, including extensive hypermethylation of the promoter and decreased expression of Runx3, a gene known to regulate allergic airway disease in mice. Importantly, we reversed the immune phenotype by treatment with a demethylating agent (5-aza-deoxycytidine). Epidemiological evidence for association of folic acid with the development of asthma in children has been mixed [52-56], but it may be that folate together with other methyl donors in the diet plays a role in this disease.

Importantly, a direct link between epigenetic control of the Th2 cytokine locus and development of allergic airway diseases was further demonstrated in mice with deficiency in the Th2 LCR [57]. A more recent study also identified a DNase 1-hypersensitive site 2 $\left(\mathrm{HS}_{2}\right)$ element in the second intron of the $/ \mathrm{I}_{4}$ gene as the strongest of all known $/ / 4$ enhancers and showed that this enhancer is strictly controlled by GATA-3 binding [58]. Moreover, TANAKA et al. [58] propose a new model in which independent recruitment of GATA-3 to locus-specific regulatory elements controls the status of the expression of genes encoding Th2 cytokines [59].

A number of other animal studies have since examined DNA methylation in the context of allergic airway disease. Fedulov et al. [60] demonstrated DNA methylation changes in splenic $\mathrm{CD}_{11 c^{+}}$dendritic cells from neonate mice born to allergic mothers (mothers sensitised and challenged with ovalbumin). BRAND et al. [61] observed increased methylation of the Ifng promoter (and increased IFN- $\gamma$ cytokine production) in $\mathrm{CD}_{4}{ }^{+} \mathrm{T}$-lymphocytes after ovalbumin sensitisation challenge. They demonstrated that methylation of the Ifng promoter is required for development of allergic airway disease by using the demethylating agent 5-aza-deoxycytidine and adoptive transfer experiments of $\mathrm{CD}_{4}{ }^{+} \mathrm{T}$-cells from sensitised/challenged animals to naïve animals and the reverse [61]. Although both demethylation and adoptive transfer experiments clearly demonstrate the importance of methylation marks in $\mathrm{CD}_{4}^{+}$ cells in development of allergic airway disease, loci other than Ifng may be important in this process and should be examined. Finally, $\mathrm{DNMT}_{3} \mathrm{~A}$, but not $\mathrm{DNMT}_{3} \mathrm{~B}$, deficiency in $\mathrm{CD}_{4}{ }^{+}$lymphocytes (conditional mutant mice) was shown to result in increased expression of IL-13 (and other Th2 cytokines), decreased DNA methylation and changes in $\mathrm{H}_{3} \mathrm{~K}_{2} 7$ acetylation/methylation in the IL-13 promoter, increased airway inflammation and AHR in the ovalbumin model of allergic airway disease [61]. This study clearly demonstrates the role of DNA methylation in controlling expression of Th2 cytokines and development of allergic airway disease in mice.

\section{DNA methylation and asthma: human studies}

While animal studies have begun to decipher the role of epigenetic regulation of gene expression associated with the development of allergic airway disease in the lung, several recent publications in human cohorts have examined DNA methylation in cells outside of the lung: peripheral blood [62], buccal cells $[63,64]$ and nasal cells [65]. These early studies have only demonstrated statistical association of DNA methylation and specific exposure or asthma phenotype, but have not elucidated the role of DNA methylation in the control of gene expression in human asthma. BRETON et al. [63] demonstrated that DNA methylation in promoters of two arginase genes (Arg1 and Arg2) is associated with exhaled NO in children with asthma from the Children's Health Study and indicates a role for epigenetic regulation of nitric oxide production. In a pilot study in the Columbia Center for Children's Environmental Health cohort, KURIAKOSE et al. [64] found that iNOS methylation was not significantly associated with exhaled NO fraction ( $\mathrm{FeNO}$ ), but was inversely associated with bronchial NO flux. This latter study emphasises the importance of careful selection of clinical parameters used in the association study. A more recent study of DNA methylation in nasal cells from 35 asthmatic children aged 8-11 years identified an inverse association of $\mathrm{FeNO}$ and promoter methylation of both 116 and iNOS [65]. Data from two independent pregnancy cohorts in Spain (discovery and validation) showed that DNA hypomethylation in Alox12 in peripheral blood of children was associated with a higher risk of persistent wheezing at age 4 years [62]. Finally, DNA from cord blood and whole blood collected at 4.5 years of age with 46 samples per time point in the rural birth cohort PASTURE showed changes 
in methylation over time in $15 / 23 \mathrm{CpC}$ regions near 10 asthma and atopy candidate genes [66]. In aggregate, these studies suggest that DNA methylation in easily obtained samples (buccal, nasal or peripheral blood cells) may be a useful biomarker for airway inflammation in paediatric research.

A recent study has also examined DNA methylation in Foxp3 and Treg function in peripheral blood from children with and without asthma and with high and low exposures to air pollution [67]. Treg-cell suppression was impaired and Treg-cell chemotaxis was reduced as a result of exposure to air pollution. Similarly, a small study of monozygotic twins discordant for asthma revealed that Treg cells from asthmatic discordant twins demonstrated decreased $\mathrm{FOXP}_{3}$ protein expression and impaired Treg function that was associated with increased levels of CpG methylation within the $\mathrm{FOXP}_{3}$ locus when compared to their non-asthmatic twin partner. In parallel, effector T-cells from discordant asthmatic twins demonstrated increased methylation of the IFN- $\gamma$ locus, decreased IFN- $\gamma$ expression and reduced effector T-cell function when compared to effector T-cells from the nonasthmatic twin [68]. Changes in DNA methylation have also been associated with the development of asthma among older smokers in the Lovelace Smokers Cohort. Comparison of 184 smokers with asthma to 511 smoker controls with a similar smoking history (chronic obstructive pulmonary disease cases excluded) identified an association of DNA methylation in the protocadherin-2O gene in sputum DNA with asthma as well as a significant synergistic interaction between methylation of protocadherin-2O and paired box protein transcription factor-5 $\alpha$ on the odds for developing asthma [69].

\section{The potential impact of epigenetics research on asthma}

While we know that inheritance, parent-oforigin, environment, in utero exposures and Th2 immunity play important roles in the aetiology of asthma, there is no welldeveloped unifying mechanism accounting for these aetiological events/triggers.
Although the hygiene hypothesis is appealing conceptually [1] and ties a number of these basic aetiological events together, there are several competing hypotheses (T-cell skewing, infection, diet, obesity, etc.) and none of them fully account for the complex interaction between host and environmental determinants of asthma. While epigenetic mechanisms not only provide a unique cause of asthma, these basic transcriptional controls potentially serve to explain some of the prevailing hypotheses underlying the development of asthma. For example, the hygiene hypothesis is dependent on activation of innate immune genes, including genes activated by the Toll-like receptors; importantly, epigenetic mechanisms control the activation of these innate immune genes and, consequently, the extent of the inflammatory response [70, 71]. Moreover, a recent study demonstrated that microbes may also operate by means of epigenetic mechanisms [72]. In this animal study, prenatal administration of the farm-derived Gram-negative bacterium Acinetobacter lwoffii F78A prevented the development of an asthmatic phenotype in the progeny and this effect was IFN- $\gamma$ dependent. Prenatal microbial exposure was also associated with a significant protection against loss of $\mathrm{H}_{4}$ acetylation in the promoter of Ifng, which was closely associated with IFN- $\gamma$ expression in $\mathrm{CD}_{4}{ }^{+}$lymphocytes as well as a decrease in $\mathrm{H}_{4}$ acetylation at the $1 / 4$ promoter. Pharmacological inhibition of $\mathrm{H}_{4}$ acetylation in the offspring abolished the asthma-protective phenotype. So while epigenetic mechanisms have the potential of changing our basic concepts about asthma, these mechanisms may not only account for the aetiological events/triggers related to asthma, but may also help to explain some of the prevailing hypotheses attributed to this disease.

Furthermore, identification of critical epigenetic marks associated with the development of asthma and influenced by specific environmental factors at certain time-points, in utero or post-natally, would allow us to advise on intake of dietary supplements and limiting harmful exposures during the critical windows when these dietary and environmental factors have the strongest influence on the development of disease. Understanding the complex interactions between in utero exposures and epigenetic vulnerability will provide insight into 
future interventions for individuals at risk for the development of allergic asthma and may lead to the prevention of this disease altogether.

However, asthma is a complex disease. Although epigenetic mechanisms may contribute to the aetiology and pathogenesis of this disease, there are multiple pieces to the asthma puzzle. The challenge will be to understand how genetic variation, transcriptome, epigenetic marks, the environment and the immune system interface with each other to result in the development of allergic and nonallergic forms of asthma.

\section{References}

1. Eder W, Ege MJ, von Mutius E. The asthma epidemic. N Engl J Med 2006; 355: 2226-2235.

2. Asher MI, Stewart AW, Wong G, et al. Changes over time in the relationship between symptoms of asthma, rhinoconjunctivitis and eczema: a global perspective from the International Study of Asthma and Allergies in Childhood (ISAAC). Allergol Immunopathol (Madr) 2012; 40: 267-274.

3. Sleiman PM, Flory J, Imielinski M, et al. Variants of DENNDiB associated with asthma in children. N EnglJ Med 2010; 362: 36-44.

4. Vercelli D. Discovering susceptibility genes for asthma and allergy. Nat Rev Immunol 2008; 8: 169-182.

5. March ME, Sleiman PM, Hakonarson H. The genetics of asthma and allergic disorders. Discov Med 2011; 11: 35-45.

6. Mathias RA, Grant AV, Rafaels N, et al. A genomewide association study on African-ancestry populations for asthma. J Allergy Clin Immunol 2010; 125: 336-346.

7. Moffatt MF, Cookson WO. The genetics of asthma. Maternal effects in atopic disease. Clin Exp Allergy 1998; 28: Suppl. 1, 56-61.

8. Holt PG, Macaubas C, Stumbles PA, et al. The role of allergy in the development of asthma. Nature 1999; 402: Suppl., B12-B17.

9. Feinberg AP, Tycko B. The history of cancer epigenetics. Nat Rev Cancer 2004; 4: 143-153.

10. Cookson WO, Young RP, Sandford AJ, et al. Maternal inheritance of atopic IgE responsiveness on chromosome 119. Lancet 1992; 340: 381-384.

11. Walley AJ, Chavanas S, Moffatt MF, et al. Gene polymorphism in Netherton and common atopic disease. Nat Genet 2001; 29: 175-178

12. Jirtle RL, Skinner MK. Environmental epigenomics and disease susceptibility. Nat Rev Genet 2007; 8: 253-262.

13. Waterland RA, Jirtle RL. Transposable elements: targets for early nutritional effects on epigenetic gene regulation. Mol Cell Biol 2003; 23: 5293-5300.

14. Cohen RT, Raby BA, Van Steen K, et al. In utero smoke exposure and impaired response to inhaled corticosteroids in children with asthma. J Allergy Clin Immunol 2010; 126: 491-497.

15. Hollingsworth JW, Maruoka S, Boon K, et al. In utero supplementation with methyl donors enhances allergic airway disease in mice. J Clin Invest 2008; 118 : 3462-3469.

16. Li YF, Langholz B, Salam MT, et al. Maternal and grandmaternal smoking patterns are associated with early childhood asthma. Chest 2005; 127: 1232-1241.

17. Henderson A), Newson RB, Rose-Zerilli M, et al. Maternal Nrf2 and gluthathione-S-transferase polymorphisms do not modify associations of prenatal tobacco smoke exposure with asthma and lung function in school-aged children. Thorax 2010; 65: 897-902.

18. Hylkema MN, Blacquière MJ. Intrauterine effects of maternal smoking on sensitization, asthma, and chronic obstructive pulmonary disease. Proc Am Thorac Soc 2009; 6: 660-662.

19. Wang L, Pinkerton KE. Air pollutant effects on fetal and early postnatal development. Birth Defects Res C Embryo Today 2007; 81: 144-154.

20. Clark NA, Demers PA, Karr C), et al. Effect of early life exposure to air pollution on development of childhood asthma. Environ Health Perspect 2010; 118: 284-290.

21. Fitzsimon N, Fallon U, O'Mahony D, et al. Mothers' dietary patterns during pregnancy and risk of asthma symptoms in children at 3 years. Ir Med J 2007; 100: Suppl., 27-32.

22. Kim HY, DeKruyff RH, Umetsu DT. The many paths to asthma: phenotype shaped by innate and adaptive immunity. Nat Immunol 2010; 11: 577-584.

23. Bouzigon $\mathrm{E}$, Corda $\mathrm{E}$, Aschard $\mathrm{H}$, et al. Effect of 17921 variants and smoking exposure in early-onset asthma. N Engl J Med 2008; 359: 1985-1994.

24. Sporik R, Holgate ST, Platts-Mills TA, et al. Exposure to house-dust mite allergen (Der p I) and the development of asthma in childhood. A prospective study. N Engl J Med 1990; 323: 502-507.

25. Oh SS, Tcheurekdjian H, Roth LA, et al. Effect of secondhand smoke on asthma control among black and Latino children. J Allergy Clin Immunol 2012; 129: 1478-1483.

26. Lloyd CM, Hessel EM. Functions of T cells in asthma: more than just $\mathrm{T}_{\mathrm{H}^{2}}$ cells. Nat Rev Immunol 2010; 10: 838-848.

27. Jones B, Chen J. Inhibition of IFN- $\gamma$ transcription by site-specific methylation during $T$ helper cell development. EMBO J 2006; 25: 2443-2452.

28. White GP, Hollams EM, Yerkovich ST, et al. CpC methylation patterns in the IFN $\gamma$ promoter in naive $\mathrm{T}$ cells: variations during Th1 and Th2 differentiation and between atopics and non-atopics. Pediatr Allergy Immunol 2006; 17: 557-564.

29. Santangelo S, Cousins DJ, Winkelmann NE, et al. DNA methylation changes at human Th2 cytokine genes coincide with DNase I hypersensitive site formation during $\mathrm{CD}_{4}{ }^{+} \mathrm{T}$ cell differentiation. J Immunol 2002; 169: 1893-1903.

30. Lee DU, Agarwal S, Rao A. Th2 lineage commitment and efficient IL-4 production involves extended demethylation of the IL-4 gene. Immunity 2002; 16: 649-66o.

31. Webster RB, Rodriguez Y, Klimecki WT, et al. The human IL-13 locus in neonatal CD4+ T cells is refractory to the acquisition of a repressive chromatin architecture. J Biol Chem 2007; 282: 700-709. 
32. Lee GR, Kim ST, Spilianakis CG, et al. T helper cell differentiation: regulation by cis elements and epigenetics. Immunity 2006; 24: 369-379.

33. Kim ST, Fields PE, Flavell RA. Demethylation of a specific hypersensitive site in the Th2 locus control region. Proc Natl Acad Sci USA 2007; 104: 17052-17057.

34. Fields PE, Kim ST, Flavell RA. Cutting edge: changes in histone acetylation at the IL-4 and IFN- $\gamma$ loci accompany Th1/Th2 differentiation. J Immunol 2002; 169: 647-650.

35. Anway MD, Cupp AS, Uzumcu M, et al. Epigenetic transgenerational actions of endocrine disruptors and male fertility. Science 2005; 308: 1466-1469.

36. Fraga MF, Ballestar E, Paz MF, et al. Epigenetic differences arise during the lifetime of monozygotic twins. Proc Natl Acad Sci USA 2005; 102: 10604-10609.

37. Heyn H, Li N, Ferreira HJ, et al. Distinct DNA methylomes of newborns and centenarians. Proc Natl Acad Sci USA 2012; 109: 10522-10527.

38. Feil R, Fraga MF. Epigenetics and the environment: emerging patterns and implications. Nat Rev Genet 2012; 13: 97-109.

39. Baccarelli $A$, Wright RO, Bollati $V$, et al. Rapid DNA methylation changes after exposure to traffic particles. Am J Respir Crit Care Med 2009; 179: 572-578.

40. Salam MT, Byun HM, Lurmann F, et al. Genetic and epigenetic variations in inducible nitric oxide synthase promoter, particulate pollution, and exhaled nitric oxide levels in children. J Allergy Clin Immunol 2012; 129: 232-239.

41. Breton CV, Byun HM, Wenten M, et al. Prenatal tobacco smoke exposure affects global and genespecific DNA methylation. Am J Respir Crit Care Med 2009; 180: 462-467.

42. Wan ES, Qiu W, Baccarelli A, et al. Cigarette smoking behaviors and time since quitting are associated with differential DNA methylation across the human genome. Hum Mol Genet 2012; 21: 3073-3082.

43. Tang WY, Levin L, Talaska G, et al. Maternal exposure to polycyclic aromatic hydrocarbons and 5'. CPG methylation of interferon- $\gamma$ in cord white blood cells. Environ Health Perspect 2012; 120: 1195-1200.

44. Guerrero-Preston R, Goldman LR, Brebi-Mieville P, et al. Global DNA hypomethylation is associated with in utero exposure to cotinine and perfluorinated alkyl compounds. Epigenetics 2010; 5: 539-546.

45. Flom JD, Ferris JS, Liao Y, et al. Prenatal smoke exposure and genomic DNA methylation in a multiethnic birth cohort. Cancer Epidemiol Biomarkers Prev 2011; 20: 2518-2523.

46. Murphy SK, Adigun A, Huang Z, et al. Genderspecific methylation differences in relation to prenatal exposure to cigarette smoke. Gene 2012; 494: $36-43$.

47. Breton CV, Salam MT, Gilliland FD. Heritability and role for the environment in DNA methylation in AXL receptor tyrosine kinase. Epigenetics 2011; 6: 895-898.

48. Kim HP, Leonard WJ. CREB/ATF-dependent T cell receptor-induced $\mathrm{FoxP}_{3}$ gene expression: a role for DNA methylation. J Exp Med 2007; 204: 1543-1551.

49. Floess S, Freyer J, Siewert C, et al. Epigenetic control of the foxp 3 locus in regulatory T cells. PLoS Biol 2007; 5: e38.

50. Huehn J, Polansky JK, Hamann A. Epigenetic contro of FOXP 3 expression: the key to a stable regulatory $\mathrm{T}$ cell lineage? Nat Rev Immunol 2009; 9: 83-89.

51. Lal G, Bromberg JS. Epigenetic mechanisms of regulation of Foxp3 expression. Blood 2009; 114: 3727-3735.

52. Whitrow MJ, Moore VM, Rumbold AR, et al. Effect of supplemental folic acid in pregnancy on childhood asthma: a prospective birth cohort study. Am J Epidemiol 2009; 170: 1486-1493.

53. Håberg SE, London SJ, Stigum H, et al. Folic acid supplements in pregnancy and early childhood respiratory health. Arch Dis Child 2009; 94: 180-184.

54. Martinussen MP, Risnes KR, Jacobsen GW, et al. Folic acid supplementation in early pregnancy and asthma in children aged 6 years. Am J Obstet Gynecol 2012; 206: 72.

55. Magdelijns FJ, Mommers M, Penders J, et al. Folic acid use in pregnancy and the development of atopy, asthma, and lung function in childhood. Pediatrics 2011; 128: e135-e144.

56. Bekkers MB, Elstgeest LE, Scholtens S, et al. Maternal use of folic acid supplements during pregnancy, and childhood respiratory health and atopy. Eur Respir J 2012; 39: 1468-1474.

57. Koh BH, Hwang SS, Kim JY, et al. Th2 LCR is essential for regulation of Th2 cytokine genes and for pathogenesis of allergic asthma. Proc Natl Acad Sci USA 2010; 107: 10614-10619.

58. Tanaka S, Motomura Y, Suzuki Y, et al. The enhancer HS2 critically regulates GATA-3-mediated $/ 14$ transcription in $\mathrm{T}_{\mathrm{H}} 2$ cells. Nat Immunol 2011; 12: 77-85.

59. Van Stry M, Bix M. Explaining discordant coordination. Nat Immunol 2011; 12: 16-17.

6o. Fedulov AV, Kobzik L. Allergy risk is mediated by dendritic cells with congenital epigenetic changes. Am J Respir Cell Mol Biol 2011; 44: 285-292.

61. Brand S, Kesper DA, Teich R, et al. DNA methylation of $\mathrm{TH}_{1} / \mathrm{TH}_{2}$ cytokine genes affects sensitization and progress of experimental asthma. J Allergy Clin Immunol 2012; 129: 1602-1610.

62. Morales E, Bustamante M, Vilahur N, et al. DNA hypomethylation at $\mathrm{ALOX}_{12}$ is associated with persistent wheezing in childhood. Am J Respir Crit Care Med 2012; 185: 937-943.

63. Breton CV, Byun HM, Wang X, et al. DNA methylation in the arginase-nitric oxide synthase pathway is associated with exhaled nitric oxide in children with asthma. Am J Respir Crit Care Med 2011; 184: 191-197.

64. Kuriakose J, Rosa MJ, Perzanowski M, et al. Bronchial nitric oxide flux may be better associated with inducible nitric oxide synthase promoter methylation. Am J Respir Crit Care Med 2012; 185: 460-461.

65. Baccarelli A, Rusconi F, Bollati V, et al. Nasal cell DNA methylation, inflammation, lung function and wheezing in children with asthma. Epigenomics 2012; 4: 91-100.

66. Michel S, Busato F, Genuneit J, et al. Farm exposure and time trends in early childhood may influence DNA methylation in genes related to asthma and allergy. Allergy 2013; 68: 355-364.

67. Nadeau K, McDonald-Hyman C, Noth EM, et al. Ambient air pollution impairs regulatory $\mathrm{T}$-cell function in asthma. J Allergy Clin Immuno 2010; 126: $845-852$.

68. Runyon RS, Cachola LM, Rajeshuni N, et al. Asthma discordance in twins is linked to epigenetic modifications of T cells. PLoS One 2012; 7: e48796.

69. Sood A, Petersen H, Blanchette CM, et al. Methylated genes in sputum among older smokers with asthma. Chest 2012; 142: 425-431.

70. Foster SL, Hargreaves DC, Medzhitov R. Gene-specific control of inflammation by TLR-induced chromatin modifications. Nature 2007; 447: 972-978.

71. Qin H, Roberts KL, Niyongere SA, et al. Molecular mechanism of lipopolysaccharide-induced SOCS-3 gene expression in macrophages and microglia. J Immunol 2007; 179: 5966-5976.

72. Brand S, Teich R, Dicke T, et al. Epigenetic regulation in murine offspring as a novel mechanism for transmaternal asthma protection induced by microbes. J Allergy Clin Immunol 2011; 128: 618-625. 